[Agr. Biol. Chem., Vol. 33, No. I, p. 18 24, 1969]

\title{
Studies on the Bacteria Isolated from Wine
}

\author{
Part IV Distribution of the Growth Factor for a \\ Bacterium Inducing Malo-lactic Fermentation
}

By Hajime Yoshizumi and Teruo Amachi

The Central Research Institute, Suntory Limited, Kita-ku, Osaka, Japan

Received April 30, 1968

\begin{abstract}
A malo-lactic fermentation (MLF) bacterium isolated from wine requires a factor contained in tomato juice for its growth. This type of the growth stimulating substance is found in several plants, particularly those belonging to fruits. The content of the factor in grapes varies depending on the varieties, degree of ripeness and harvest time. From these observation the relationship between the induction of MLF and the activity of the factor of grapes was discussed.
\end{abstract}

Bacterial conversion of malic acid to lactic acid by certain Lactobacilli designated as malolactic fermentation (MLF) occurs following after alcoholic fermentation in wine making. MLF is of importance not only in the accompanying reduction of acidity in wine (the conversion of a dicarboxylic to a monocarboxylic acid) but also in the improvement of wine quality by developing a certain aged flavor.

One of the authors" previously reported the relationship between MLF and the bacterial flora in wine musts, and isolated some malic acid dissimilatable strains from MLF occurred wine. Based on taxonomical investigation ${ }^{21}$ the strains were classified into three groups, and one of these three groups, represented by strain WNB-75 which played the leading part in MLF, was found to require exactingly some factor contained in tomato juice for its growth. The identification of this growth factor is necessary for the further investigation of the physiological characters of these strains.

In the earlier paper Francot and Geoffrory ${ }^{3 \prime}$

1) H. Yoshizumi, Nippon Nogeikagaku Kaishi, 37, 326 (1963).

2) H. Yoshizumi, Agr. Biol. Chem., 27, 590 (1963). showed that the autolysates of yeast in lees contributed the MLF bacteria to multiply and that the MLF was consequently induced when wine was left in turbid without racking. It was also reported that addition of riboflavin or dry powder of the mycelium of Aspergillus species promoted the propagation of the MLF bacteria. ${ }^{41}$ Bocker $^{51}$ had pointed out that MLF was promoted by alkali and alkaline earth metals in wine, especially by potassium. Müller-Thurgau and Osterwalder ${ }^{6}$ used the agar medium of pear or grape juice for the isolation of bacteria in wine, but it took two or three weeks to obtain the maximum growth. Ingraham $^{71}$ examined the medium for the growth of malic acid dissimilatable bacteria in California wine, and found out that unknown growth factors(s) present in tomato juice or liver extract was necessary for the maximum growth in addition to the customary ingredients

3) P. Francot and P. Geoffrory, Le Vigneron Champenois, 75, 425 (1954).

4) E. Peynaud, Am. J. Enol., 7, 150 (1959).

5) H. Bocker, Zbl. Bakt. Par. Abt. II, 112, 337 (1959).

6) H. Müller-Thurgau and A. Osterwalder, Chem. Abst., 8, 1483, (1914).

7) J. Ingraham, Am. J. Enol. Viticult., 2, 1 (1960). 
of the medium. Nonomura et $a .^{81}$ have reported, however, that the nutrients in tomato juice could be replaced by $\mathrm{Mn}^{2+}$ and fructose for the growth of certain MLF bacteria.

The present paper deals with the distribution of the growth factor for strain WNB-75 in nature, and also discussion of the relationship between MLF induction and the factor activity in several grape varieties.

\section{METHODS}

Stock culture and inoculum. The test organism, WNB-75, was isolated from MLF occurred wine. The composition of the stock culture medium is shown in Table I. The stock culture was maintained by monthly transfer in stabs under liquid paraffin layer of $1.5 \mathrm{~cm}$ thickness. The organism was taken out from stab culture and suspended into sterile saline (about $10^{6}$ cells per $\mathrm{ml}$ ).
In case of grape, the fruit was separated into rind, flesh and seed, and each part was crushed by mortar and extracted with boiling water followed by centrifugation to remove insoluble materials.

Bioassay method. The growth stimulating activity for strain WNB-75 was measured spectrophotometrically by using bioassy method. Graded amounts of an extract solution for determination were added to a series of tubes containing $2 \mathrm{ml}$ of the double strength basal medium, and total volume in each tube was made to $4 \mathrm{ml}$ with water. Cultures were carried out using the Bausch and Lomb's spectrophotometer tubes. The medium was sealed with liquid paraffin of $1.5 \mathrm{~cm}$ thickness and autoclaved $\left(1 \mathrm{~kg} / \mathrm{cm}^{2}, 5 \mathrm{~min}\right)$. After cooling, each tube was inoculated with $0.1 \mathrm{mI}$ of the inoculum suspension and incubated at $27^{\circ} \mathrm{C}$ for one or two weeks. Growth response was followed by measuring the optical density at $560 \mathrm{~m} \mu$ (Bausch and Lomb's spectronic 20 photometer). The minimal amount of the factor in the basal medium for suf-

Table I. The Composition of the Stock Culture and the Basal Medium (Double Strength)

$\begin{array}{lrll}\text { D-Ribose } & 2.0 \% & \mathrm{KH}_{2} \mathrm{PO}_{4} & 0.1 \% \\ \text { or }\left\{\begin{array}{l}\text { D-Glucose } \\ \text { D-Fructose }\end{array}\right. & 1.0 \% & \mathrm{NaCl}_{4} & 0.025 \% \\ \text { Yeast Extract (Daigo Eiyo) } & 1.0 \% & \mathrm{CaCl}_{2} \cdot 2 \mathrm{H}_{2} \mathrm{O} & 0.025 \% \\ \text { Polypeptone (Daigo Eiyo) } & 1.0 \% & \mathrm{MgSO}_{4} \cdot 7 \mathrm{H}_{2} \mathrm{O} & 0.025 \% \\ \text { Tomato Juice* } & 1.0 \% & \mathrm{KCl} & 0.025 \% \\ \text { Agar* } & 20.0 \% & \mathrm{MnSO}_{4} \cdot 4 \mathrm{H}_{2} \mathrm{O} & 0.0006 \% \\ & 3.0 \% & \mathrm{pH} 5.0 & \end{array}$

* Omitted from the basal medium for the estimation of the activity of the factor.

Basal medium. The composition of the basal medium is shown in Table $I$. This medium fails to allow normal growth of strain WNB-75 and the addition of the unknown growth factor which exists in tomato juice is necessary for a maximal growth to occur.

Preparation of extracts. The extracts of various vegetables, fruits, malt, meat and livers were prepared by the following procedures: a raw material was crushed in mortar or electric mixer and was heated at $100^{\circ} \mathrm{C}$ for $5 \mathrm{~min}$, and the extracted solution was separated from the insoluble fraction by centrifuge.

8) H. Nonomura, T. Yamazaki and I. Ohara, The Ann. Meet. Agr. Chem. Soc. Japan, (1965). ficient growth was defined as one unit of the activity of the growth factor.

\section{RESULTS}

\section{Determination of the activity of the growth factor}

Tomato juice was a good source of the unidentified growth factor and has been used as an arbitrary standard to determine the activity. Graded amounts of tomato juice were added to the basal media, followed by the inoculation of strain WNB-75, and the growth response was determined. Strain WNB-75 was 

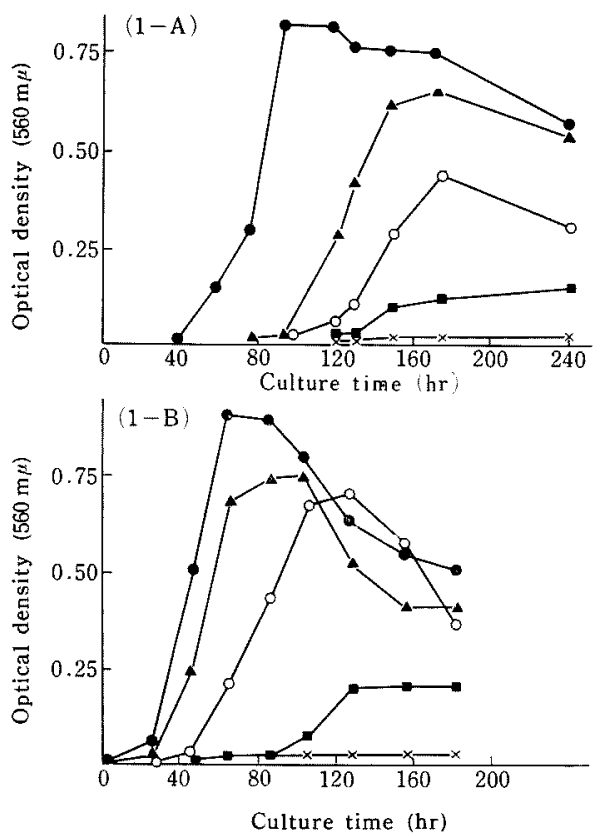

FIG. 1. Relationship between Tomato Juice (TJ) Concentration and the Growth of the Strain WNB75.

Carbon source used:

(1-A) D-Ribose

(1-B) D-Glucose and D-Fructose

- TJ $20 \%$ was added to the basal medium,

A-A TJ $10 \%$,

O-O TJ $5 \%$

--E TJ 2.5\%,

$x-\mathrm{x}$ TJ $1.0 \%$

unable to assimilate sugars as the sole carbon source except D-ribose, but it could grow normally on co-existed D-glucose and D-fructose. The similar phenomenon has been previously observed in L. fructosus by Kodama."

Figure 1-A shows the growth responses to the amounts of tomato juice added when Dribose was used as the carbon source. The growth responses in media containing $\mathrm{D}$-glucose and D-fructose are shown in Fig. 1-B. After stationary phase the decrease of the optical density due to the sedimentation of the cells

9) R. Kodama, Nippon Nogeikagaku Kaishi, 31, 105 (1957). was observed in each case. In D-ribose medium the proportionality was observed between the amount of tomato juice added (from 1.0 to $20.0 \%$ ) and the length of lag time as well as a number of the cells at the stationary phase. In the medium containing glucose and fructose, however, a sudden drop in growth rate was found at the concentration of tomato juice lower than 2.5\%. The results shown in Fig. 1 also suggest that more than $5 \%$ of tomato juice is necessary to be added for the normal growth of strain WNB-75 under the test condition independent of sugar as a carbon source.

Thus, one unit of the activity of the growth factor has been defined as that equivalent to the amount of the factor contained in $0.2 \mathrm{ml}$ of standard tomato juice. Samples for determination of activity were diluted up to give an estimated 0.25 to 0.5 unit per $\mathrm{ml}$ of medium and the activity of the factor was assayed.

\section{Distribution of the growth factor for strain $W N B-75$ in natural sources}

The fact that the strain WNB-75 grows vigorously in wine naturally suggests the existence of the growth factor in grapes. Table II shows the distribution of the factor in the various natural sources with high activities in fruits, particularly in orange, melon, and loquat. Among the many vegetables tested, a high activity was also observed in lotus bulb and spinach, but none in carrot, radish, and

TABLE II. Distribution of the Factor

$\begin{array}{lclc}\text { Sample } & \begin{array}{c}\text { Factor } \\ \text { activity } \\ (\mathrm{u} / \mathrm{ml})\end{array} & \text { Sample } & \begin{array}{c}\text { Factor } \\ \text { activity } \\ (\mathrm{u} / \mathrm{ml})\end{array} \\ \text { Orange } & 15 & \text { Burdock } & 5 \\ \text { Lemon } & 15 & \text { Lotus bulbs } & 20 \\ \text { Apple } & 2.5 & \text { Cucumber } & 0 \\ \text { Pear } & 10 & \text { Potato } & 1 \\ \text { Peach } & 10 & \text { Cabbage } & 2.5 \\ \text { Loquat } & 20 & \text { Spinach } & 20 \\ \text { Banana } & 5 & \text { Malt extract } & 0 \\ \text { Melon } & 20 & \text { Bouillon } & 0 \\ \text { Carrot } & 0 & \text { Liver extract } & 1 \\ \text { Radish } & 0 & & \end{array}$




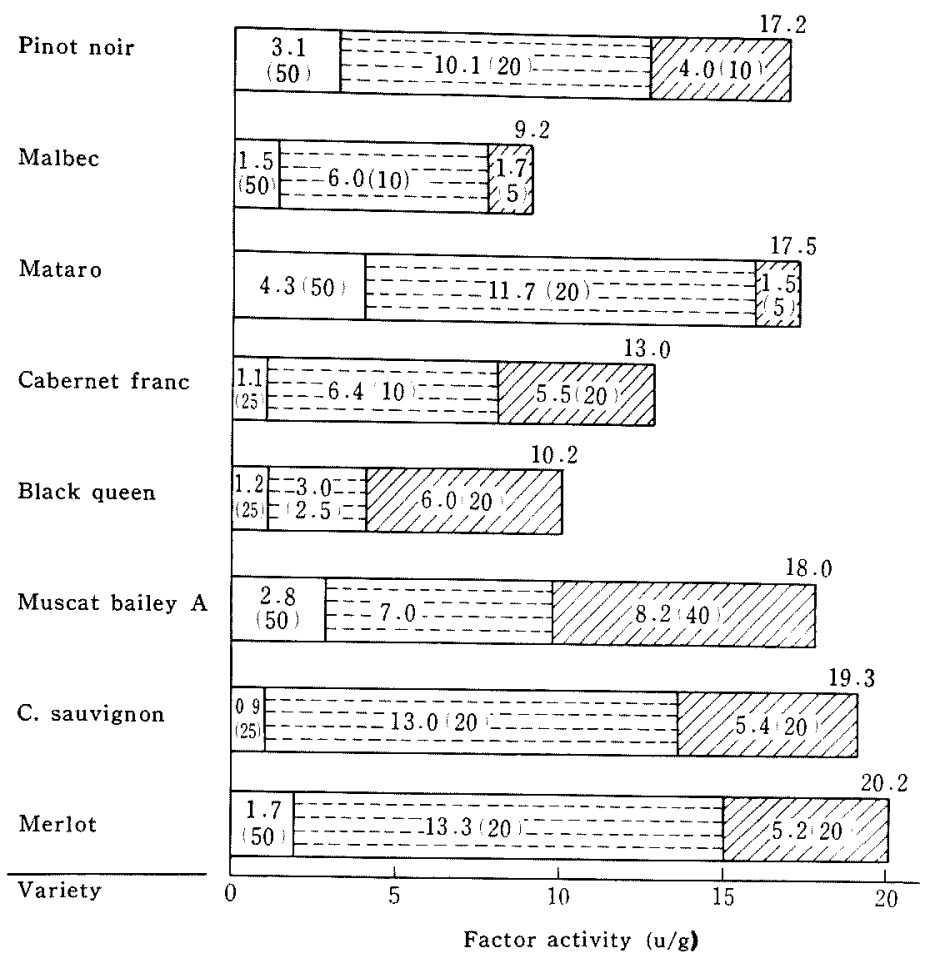

FIG. 2. The Factor Activity in Grape for Red Wine.

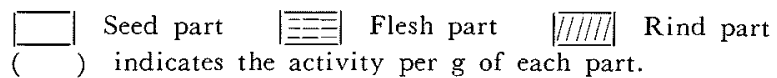

cucumber. No activity was found in malt or meat extract, and a little in liver extract.

If there are any differences in the activity of the growth factor depending on grape varieties, the facility of MLF occurrence in wine may be influenced by the varieties of grapes. The differences in the distribution and the content of the growth factor between the parts of fruit may also affect the MLF occurrence during the wine making. Figure 2 shows the distribution of the activity of the factor in rind, flesh and seed of the varieties of grapes for red wine, and Fig. 3 summarizes those in the varieties of grapes for white wine. The results indicate that the factor activities differ in the varieties of grapes each other and also in the various parts of the fruit. For instance, the factor activities in Muscat bailey A, Pinot blanc, Chardonnay, and Traminer varieties were high in rind, but those in Pinot griss and Rose ciotat varieties contain much more growth factor in the part of flesh, and the varieties of grapes for red wine show, in general, higher activities than those for white wine.

In Fig. 4 the distribution of the activity of the factor in red wine varieties with the different harvest date and ripeness is summarized. For Muscat bailey A variety the factor activities of ripe and unripe fruits harvested on September 24 were compared with those of ripe fruits harvested on October 14. The 


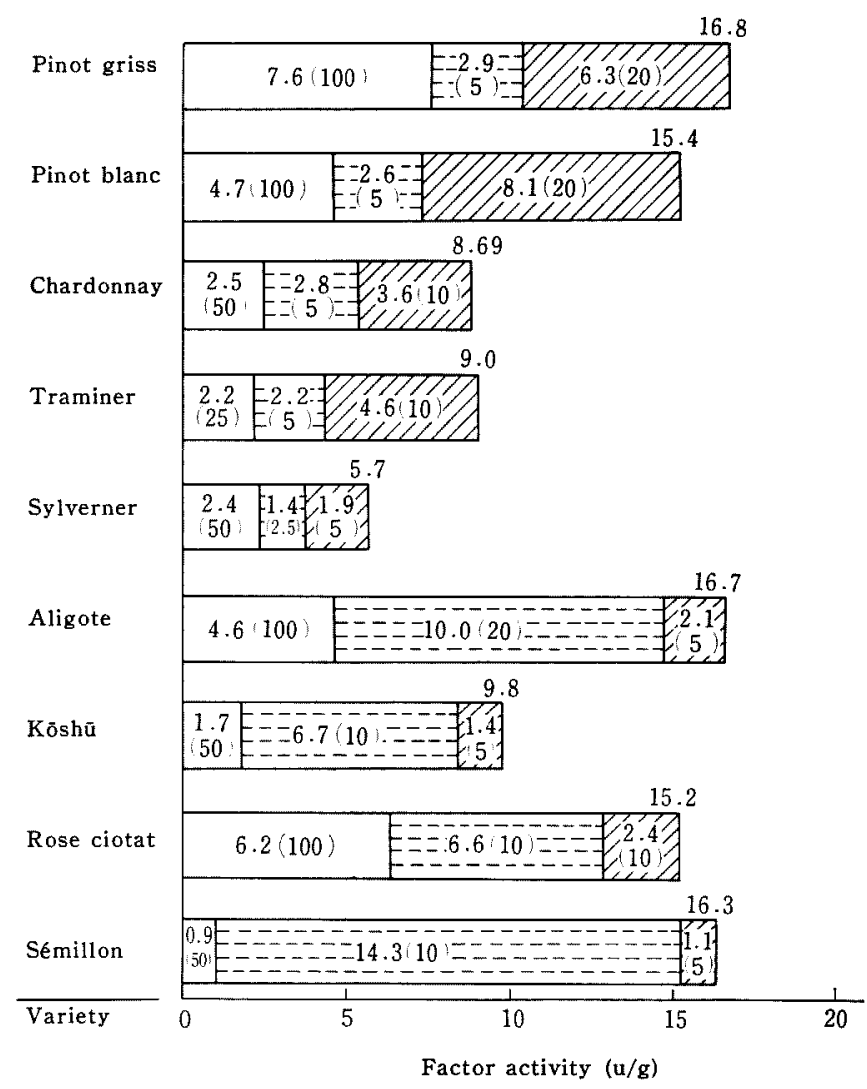

FIG. 3. The Factor Activity in Grape for White Wine.

Seed part
$($,$) indicates the activity per \mathrm{g}$ in each part.

activity was markedly increased in every variety when the harvest date was delayed for twenty days. The results also indicate the content of the factor in grapes to be rather independent of the ripeness, but is much influenced by the harvest date with the exception of Black queen. Figure 5 shows the relationship between ripeness and the activity of the growth factor in the varieties of grapes for white wine. In these cases the increases of the activities of the growth factor were also found by delaying the harvest date.

The activity of the factor of foliage part of the grape vine was also determined as shown in Fig. 6 and was found to be higher than that in the grape juice. The activities of the factor were also examined in each parts of tomato plant. As shown in Table III, the concentration of the factor in foliage was about twice as much as in fruit, and none in stem and a little in root.

\section{DISCUSSION}

As shown in Table II, Figs. 2 and 3, the growth promoting substance of MLF bacteria was found to occur widely in various fruits and vegetables in addition to tomato juice. 

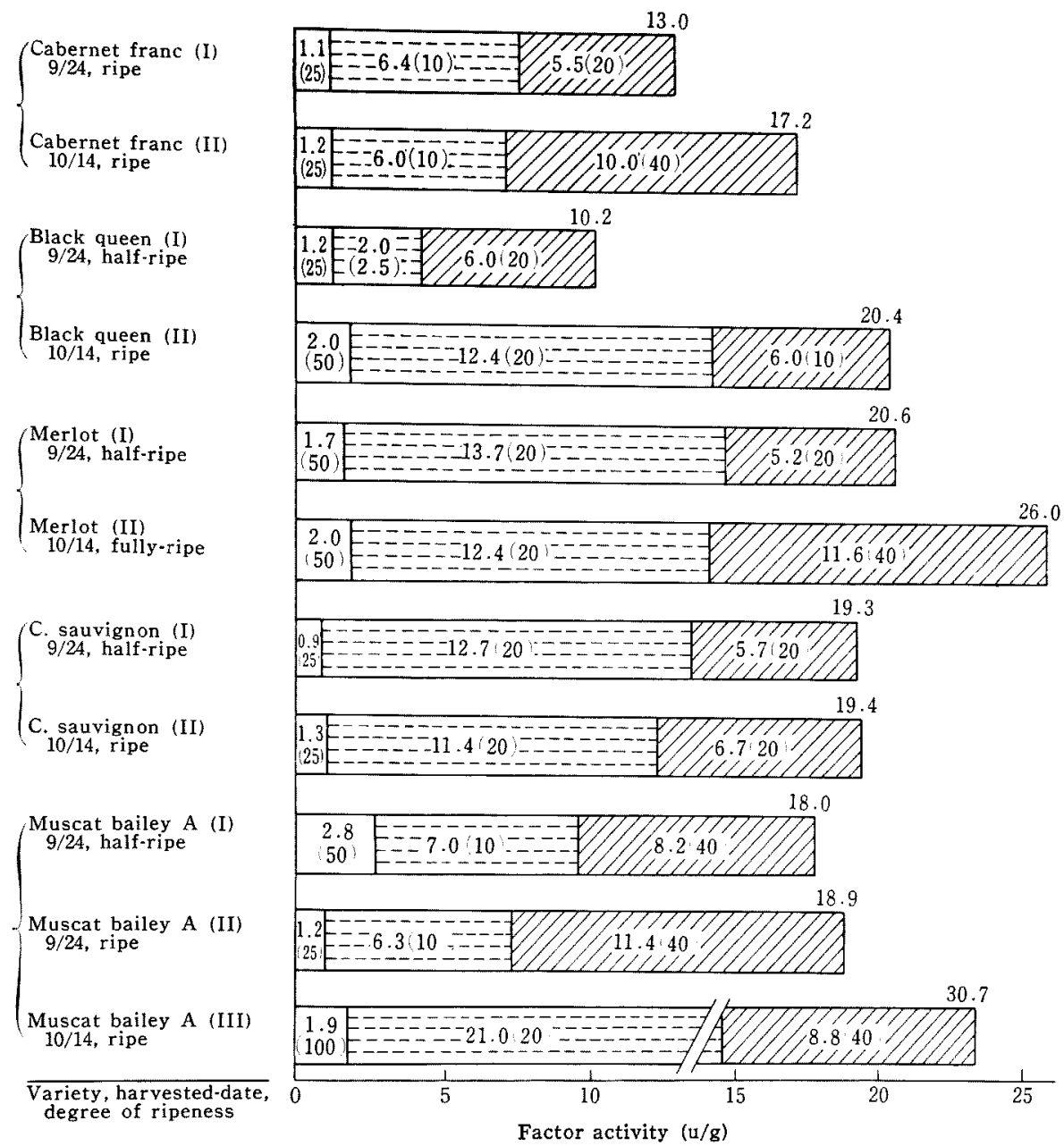

FIG. 4. Relationship between Factor Activity and the Harvest Time, Degree of Ripeness and Variety of Grapes for Red Wine.

Seed part
$(\square$ indicates the activity per $\mathrm{g}$ in each part.

The activity of the factor was not found in strate whether the factor(s) found in several radish, carrot or cucumber, and neither in fruits and vegetables is identical with that bouillon nor malt extract. However, since crude samples were dealt to determine the factor activity, there remained the possibility that growth promoting and inhibiting substances co-existed in some cases. Moreover, further investigation must be done to demonof tomato juice or not.

Estimating the activity of the growth factor in the nine varieties of grapes for white wine and eight varieties of grapes for red wine, the latter showed slightly higher activity of the factor. This accords with the fact that MLF 

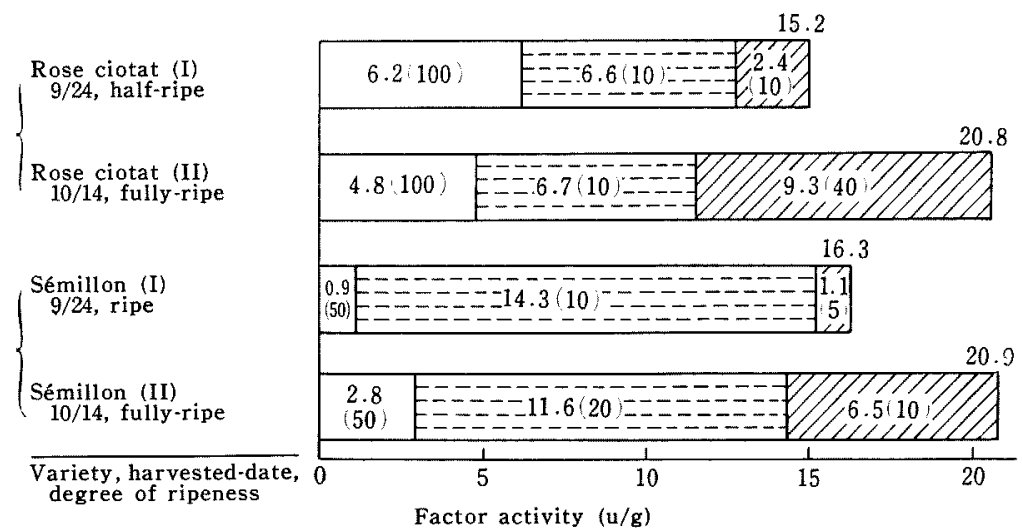

FIG. 5. Relationship between Factor Activity and the Harvest Time, Degree of Ripeness and Variety of Grapes for White Wine.

Seed part
$($,$) indicates the activity per \mathrm{g}$ in each part.

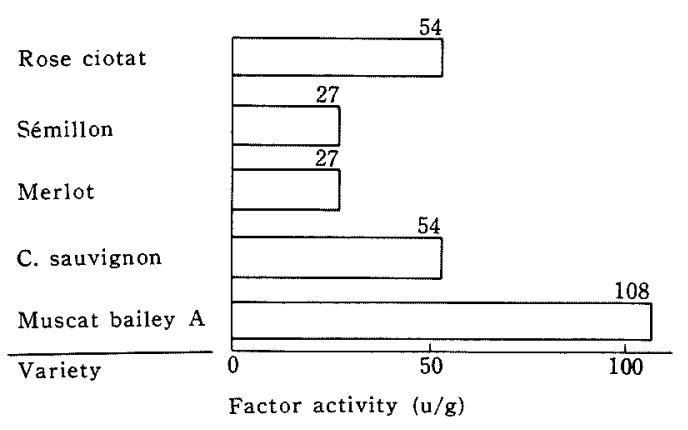

FIG. 6. The Factor Activity in Foliage Part of the Grape Vine.

Table III. The Factor Activity in Tomato PLANT

$\begin{array}{lc}\quad \text { Part } & \text { Factor activity }(\mathrm{u} / \mathrm{ml}) \\ \text { Fruit } & 5 \\ \text { Foliage } & 10 \\ \text { Stem } & 0 \\ \text { Root } & 2\end{array}$

is apt to occur in red wine than in white wine.

It is generally known that MLF bacteria can not grow below $\mathrm{pH} 3.1$ in wine must. Since the optimal pH of strain WNB-75 is 5.0, it is convenient for MLF to shift $\mathrm{pH}$ in must as higher as possible. Thus, the growth of MLF bacteria may be accelerated by the decrease of acidity. Besides, the activity of the growth factor can be increased by delaying the harvest time of the grapes, and MLF may proceed at an early stage. Owing to the higher activity of the factor in rind, the MLF bacteria (WNB-75) may be hard to grow in white wine which is fermented without rind.

The characterization of the growth factor may be of interest not only in the problems on the physiology of MLF bacteria but also in the plant chemistry. The properties of the factor separated from tomato juice will be reported in the next paper in detail.

Acknowledgements. The authors would like to express their gratitude to Mr. K. Saji, president of Suntory Ltd., for his consent to publish this paper. The authors also wish to express much thanks to Prof. J. Fukumoto, Prof. Y. Satomura and Associate Prof. T. Yamamoto, Osaka City University, Prof. Y. Obata, Hokkaido University, for their valuable suggestions. Thanks are also due to Dr. S. Kusumoto, Dr. Y. Terashima and Dr. S. Senoh, our Institute, for their encouragements throughout the work; and to Miss K. Kitamura, a member of the authors' Laboratory, for her skillful assistance. 